\title{
LA POLISEMIA LÉXICA SEGÚN GRAMÁTICOS Y LEXICÓGRAFOS CHILENOS DEL SIGLO XIX: ACTITUDES E IDEOLOGÍAS LINGÜISTICAS*
}

\author{
LEXICAL POLYSEMY ACCORDING TO CHILEAN NINETEENTH \\ CENTURY GRAMMARIANS AND LEXICOGRAPHERS: \\ LINGUISTIC ATTITUDES AND IDEOLOGIES
}

\section{DARÍO ROJAS **}

\section{RESUMEN}

El presente trabajo analiza las actitudes hacia la polisemia léxica sostenidas por gramáticos y lexicógrafos chilenos hispanohablantes del siglo XIX. Las actitudes son principalmente negativas: los autores estudiados consideran que las palabras deberían tener solo un significado (el que les es "propio"). Esta creencia se explica en el marco de la ideología de la lengua estándar, que tiene como meta la reducción de la variación lingüística: la polisemia es objeto de valoración negativa porque implica variación semasiológica, lo cual además es asociado con un desmedro de la función comunicativa del lenguaje. Adicionalmente, destacamos la motivación glotopolítica de dicha ideología y actitudes hacia la polisemia: la estandarización lingüística forma parte del proceso de consolidación del Estado nacional chileno.

Palabras clave: Polisemia, ideologías lingüísticas, actitudes lingüísticas, historiografía lingüística, estudios del lenguaje en Chile.

\section{ABSTRACT}

This paper analyzes the attitudes towards lexical polysemy in the works of Chilean Spanish-speaking grammarians and lexicographers from the 19th century. The attitudes are mainly negative: the authors consider that words should have only one mean-

* Trabajo realizado con el apoyo financiero de CONICYT (proyecto FONDECYT Regular 1150127) y del Programa U-Apoya, Universidad de Chile. Una versión preliminar de este trabajo fue presentada en la 13th International Conference on the History of the Language Sciences (ICHoLS XIII), Vila Real (Portugal), 25-29 de agosto de 2014. Agradezco a los evaluadores anónimos del presente artículo por sus útiles sugerencias.

** Doctor en Filosofía y Letras, Departamento de Lingüística, Facultad de Filosofía y Humanidades, Universidad de Chile. Santiago, Chile. Correo electrónico: darioroj@u.uchile.cl 
ing (the "proper" meaning). Such a belief can be best understood within the frame of standard language ideology. As this language ideology aims for reduction of variation, semasiological variation (i.e., polysemy) becomes the subject of negative evaluation, which also undermines the communicative function of language. Moreover, we underline the political motivations of such ideology and attitudes towards polysemy: linguistic standardization is part of the consolidation process of the national Chilean State.

Keywords: Polysemy; language ideologies; language attitudes; linguistic historiography; Chilean language studies.

Recibido: 05.03.15. Aceptado: 03.03.16.

\section{INTRODUCCIÓN}

$\mathrm{E}$

L PROPÓSITO DEL presente trabajo es identificar las actitudes que un grupo de gramáticos y lexicógrafos chilenos hispanohablantes del siglo XIX mostraba hacia la existencia de más de un significado para una palabra dada (esto es, la polisemia léxica), y explicar estas actitudes en el marco de la ideología lingüística hegemónica de ese contexto histórico: la ideología de la lengua estándar (Milroy, 2001). Con esto, pretendemos hacer una pequeña contribución a la historiografía intelectual chilena, pues la relevancia de los estudios de historia de las ideas lingüísticas sobrepasa por mucho el ámbito de la lingüística, en la medida en que dichas ideas forman parte de y se relacionan con imaginarios más amplios que revelan aspectos epistemológicos, morales, políticos y culturales, en general, de las comunidades en que han surgido.

Debemos hacer dos aclaraciones antes de comenzar la exposición. Primero, nuestro estudio no trata sobre el término polisemia como tal. El francés Michel Bréal (1832-1915) fue el primero en utilizar este término en 1887, aunque la "multiplicidad de significados" fue de hecho estudiada desde mucho antes bajo otras denominaciones (Nerlich, 2003, p. 49). En nuestras fuentes, los autores solo escriben acerca de los múltiples significados de ciertas palabras sin preguntarse sobre la naturaleza de ese hecho lingüístico y, más importante aún, nunca utilizan el término polisemia ${ }^{1}$.

\footnotetext{
${ }^{1}$ En las ciencias del lenguaje de hoy, por polisemia se entiende la propiedad de algunos signos (sean unidades léxicas o construcciones) cuyo contenido corresponde a "una red estable (aunque dinámica) de interpretaciones que se encuentran asociadas entre sî” (Rojas, 2011, p. 166); es decir, el signo debe tener más de un "sentido" o "significado" y estos tienen entre sí alguna relación (normalmente de tipo metafórico o metonímico), además de mostrar síntomas de antagonismo y discreción (Cruse, 2004). La polisemia es un tipo específico de ambigüedad (existencia de más
} 
En segundo lugar, cuando nos refiramos a las obras de nuestros autores hablaremos de "estudios del lenguaje" en lugar de "la lingüística", porque lo que hoy conocemos bajo este último nombre no se había establecido todavía como disciplina científica en Chile en ese momento. La profesionalización e institucionalización (una "cientifización") de los estudios del lenguaje en este país empezó tan solo en la última década del siglo XIX, con la llegada a la Universidad de Chile de los profesores alemanes Rodolfo Lenz (1863-1938) y Federico Hanssen (1857-1919), formados en la filología histórico-comparada europea, que constituía la lingüística científica de la época (Sand, 1958). En cambio, los autores estudiados en este trabajo son "lingüistas aficionados" o "académicos no lingüistas" (Wilton y Wochele, 2011): abogados, políticos, sacerdotes, periodistas, escritores, etc., que tercian en los debates sobre la lengua española por diversos motivos.

Por las dos razones referidas, el presente estudio se enmarca mejor en la historiografía de las ideologías lingüísticas (Blommaert, 1999), hecha desde un punto de vista antropológico-histórico, que en la historiografía lingüística en su corriente principal (Swiggers, 2012). Al asumir la perspectiva antropológico-histórica, las nociones de ideología y actitud pasan a cumplir un papel explicativo central, pues destacan la historicidad, materialidad y circunstancia sociocultural de la reflexión metalingüística (sea especializada o no). Entendemos por ideología lingüistica un conjunto organizado de creencias compartidas por un grupo cultural acerca de la naturaleza, la función y otros aspectos del lenguaje o las lenguas (Kroskrity, 2010). El concepto de actitud lingüística, por su parte, se refiere a una tendencia a evaluar de manera positiva o negativa un determinado rasgo lingüístico específico, una variedad lingüística o a ciertos hablantes (Garrett, 2010). Aunque no hay una relación de determinación necesaria ni unidireccional, es sabido que las actitudes se ven motivadas por las creencias que conforman las ideologías (Maio et al., 2006), de modo que resulta pertinente considerarlas de manera conjunta.

Antes de exponer nuestro análisis, reseñaremos brevemente el contexto sociohistórico y lingüístico-ideológico en que se despliegan los discursos metalingüísticos que estudiamos.

de una interpretación posible para un signo), propiedad del lenguaje que, a pesar de que en ciertos periodos (como el estudiado acá) ha sido vista como una amenaza, hoy se considera que es condición de eficiencia para el lenguaje humano, dada la existencia de elementos de contexto (Piantadosi, Tily y Gibson, 2012).

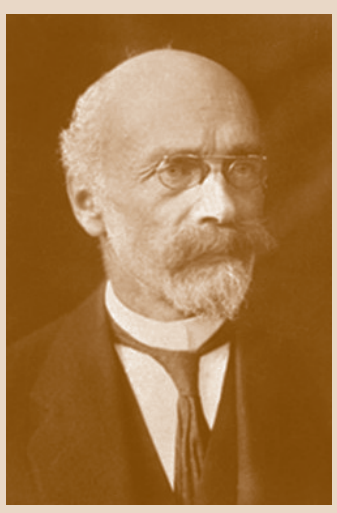

R. Lenz

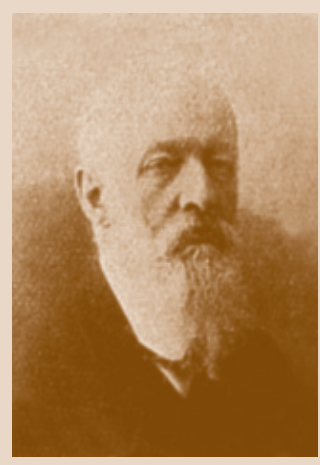

F. Hanssen 


\section{CONTEXTO DE LOS AUTORES ESTUDIADOS}

Después de casi 300 años de dominio colonial español, Chile se convirtió en un Estado-nación independiente, en un proceso que se inició en 1810 y tuvo su punto culminante en 1823. Después de un período de anarquía y ensayos constitucionales que terminaron con una guerra civil, comenzó un periodo conocido como la República Conservadora (1830-1861). Durante este período, la élite gobernante de habla española organizó un Estado fuerte, autoritario y centralizado que tenía como su principal objetivo asegurar el orden social y la estabilidad (Collier y Sater, 2004, p. 53).

Este período de la historia política chilena dejaría una marca culturalmente conservadora en el pensamiento de la élite hispanohablante, a pesar de que una parte importante de los intelectuales y políticos chilenos de la época adhirieron a los ideales liberales (Subercaseaux, 2011), especialmente durante la República Liberal (1861-1891). Con "culturalmente conservador" nos referimos a que el grupo gobernante buscó una transición gradual del orden colonial a la independencia, en lugar de una revolución política radical y una transformación cultural completa. Por lo tanto, muchas de las prácticas culturales del pasado colonial persistieron a pesar del nuevo orden político (Collier y Sater, 2004, p. 40). Entre estas prácticas culturales se encontraba la predominancia de la lengua española entre la élite chilena y la prevalencia de un horizonte normativo peninsular (la norma castellana).

Fue solo después de la independencia que la lengua española (la de los antiguos gobernantes, la Corona española) se convirtió en un problema cultural para los intelectuales chilenos. Durante la primera mitad del siglo, los dos principales modelos culturales sobre el lenguaje que circularon en Chile fueron el modelo racionalista y el modelo romántico, en el sentido que Geeraerts ([2003] 2006) da a estos términos.

Los racionalistas pensaban que el idioma español debía ser el medio de comunicación entre las nuevas naciones independientes de América y que debía tener uniformidad a lo largo de todos los territorios en los que se hablaba (incluyendo España), favoreciendo de esta manera la imposición de una norma suprarregional (Arnoux, 2008). En consecuencia, los dialectos locales no estándares se convirtieron en objeto de fuertes actitudes negativas, porque supuestamente impedían la deseada unidad y uniformidad de la lengua. El más famoso e influyente de los racionalistas fue el político, abogado, escritor, filólogo y gramático venezolano Andrés Bello (17811865), que llegó a Chile en 1829 y desempeñó un papel destacado en la formación de la República chilena (Jaksić, 2001). 
Por otro lado, los románticos pensaban que se debía transformar el dialecto vernáculo en lengua nacional, pues dicha variedad expresaba la auténtica identidad del pueblo chileno. El argentino Domingo Faustino Sarmiento (1811-1888), quien también llegó a Chile y participó en los debates políticos de la época, fue uno de los principales pensadores románticos de la época (Velleman, 2002).

La opinión racionalista, lingüísticamente conservadora, llegó a ser casi hegemónica entre los intelectuales chilenos de la época. Esto condujo a un proceso local de gramatización (Auroux, 2009), que se manifestó principalmente a través de diccionarios y gramáticas que recogían los "errores" lingüísticos (es decir, las características dialectales) y mostraban cómo hablar "correctamente" el español, esto es, de acuerdo con la norma castellanizante codificada por la Real Academia Española. Es decir, estos códigos (diccionarios y gramáticas) tenían una función estandarizadora (Rojas, 2010), que a su vez debe entenderse como parte del proceso de construcción y consolidación del Estado-nación.

Los discursos y las prácticas metalingüísticas de este período se enmarcan en un proceso de estandarización lingüística, proceso que tiene como objetivo principal la supresión de la variabilidad opcional (Milroy y Milroy, 1999, p. 22). La ideología lingüística asociada a este tipo de procesos, la ideología de la lengua estándar (Milroy, 2001), es la que subyace a estos discursos. Por poner un ejemplo representativo, el del lexicógrafo Zorobabel Rodríguez, su discurso metalingüístico se articula sobre el concepto de corrección y creencias tales como la preeminencia de un código preexistente al uso y codificado en las obras de la Academia, el valor modélico del lenguaje de las personas educadas y de los escritores clásicos españoles, o la consideración negativa del préstamo léxico, entre otras (Avilés y Rojas, 2014, pp. 157-158).

\section{ACTITUDES HACIA LA POLISEMIA}

En el contexto chileno podemos encontrar una primera muestra de actitudes negativas hacia la polisemia en los escritos del influyente Andrés Bello. En el prólogo de su Gramática castellana destinada al uso de los americanos (1847), el chileno-venezolano escribe acerca de los comportamientos lingüísticos que perjudican la unidad de la lengua española. Entre estas conductas, está lo que hoy conocemos como "polisemia": 
Hay otro vicio peor, que es el prestar acepciones nuevas a las palabras y frases conocidas, multiplicando las anfibologías de que por la variedad de significados de cada palabra adolecen más o menos las lenguas todas, y acaso en mayor proporción las que más se cultivan, por el casi infinito número de ideas a que es preciso acomodar un número necesariamente limitado de signos (Bello, 1847, p. xi).

Bello creía que, en una situación ideal, cada palabra debía tener un significado, y este significado, evaluado como el "correcto" o el "propio", era generalmente: (a) el que registraba la Real Academia Española en su diccionario; (b) el más cercano al significado etimológico; o (3) aquel utilizado por los escritores de la época clásica de la literatura española.
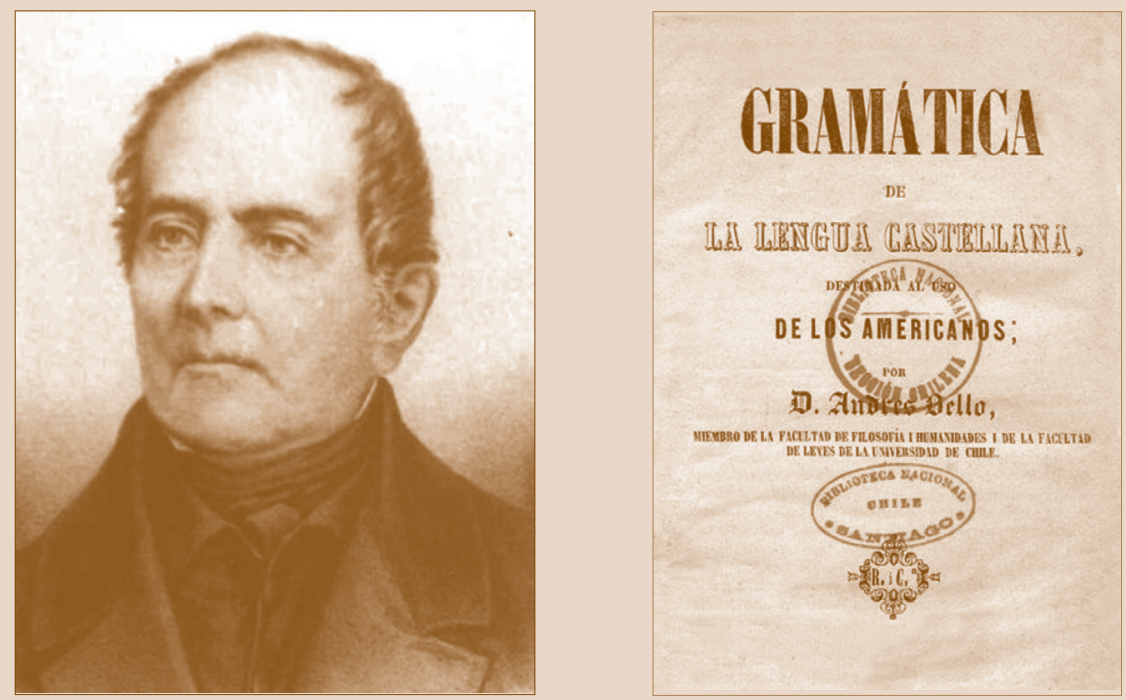

Andrés Bello y su Gramática de la lengua castellana. Imágenes de www.memoriachilena.cl

Algunos años más tarde, en un comentario crítico acerca de las Correcciones lexigráficas de Valentín Gormaz (escrito alrededor de 1860 y publicado póstumamente; véase Bello, 1883), Bello critica la utilización chilena del adjetivo sendos con el significado de 'grande'. De acuerdo con "su primitiva i jenuina significación" (Bello, 1883, p. lxxv), sendos solo puede tener un sentido distributivo (con sendas lanzas 'cada uno con una lanza', y no 'con grandes lanzas'), que es el que aparece en escritores castellanos de la época clásica. En este mismo sentido, es revelador que en uno de los raros casos 
en que Bello abogó por un provincialismo, como es el caso de concho, 'sedimento', haya argumentado que sus posibles sustitutos castellanos, borra, broza y hez, "tienen el inconveniente de prestarse a sentidos diferentes" (Bello, 1883, p. lxxiv); es decir, no son buenos sustitutos porque son polisémicos, a diferencia de concho, que tiene un solo significado.

Si se tiene en cuenta la gran influencia de Bello en la historia intelectual de Chile (no solo en asuntos idiomáticos, sino también en la educación, la política y el derecho, entre otros ámbitos), no sería ninguna sorpresa que autores posteriores adoptaran una actitud similar hacia la polisemia. Un buen ejemplo de la persistencia de la actitud negativa de Bello hacia la polisemia son las Correcciones lexigráficas sobre la lengua castellana en Chile (1860), un libro didáctico sobre el "español correcto" escrito por Valentín Gormaz (1820-1884). En el prólogo de esta obra, Gormaz se refiere a algunas de las consecuencias negativas de la falta de cultivo y enseñanza idiomática, falta que considera común en el Chile de ese momento. Entre estas consecuencias, se encuentran los malentendidos causados por la polisemia.

En una nota a pie de página, Gormaz describe vívidamente las consecuencias casi catastróficas que la polisemia de la palabra pescador (que significaba tanto 'persona que captura peces' como 'persona que vende pescado’ en el español chileno de la época) podría tener en la vida cívica:

En efecto, supóngase la existencia de un precepto legal que prohibiera cargar armas. Supóngase tambien que se esceptuara en él a los carniceros, pescadores y demas que las necesitan para su mercado, y que por efecto de propiedad, se empleara la voz pescador en lugar de pescadero como es tan jeneral entre nosotros. ¿Qué haria el juez con un vendedor de pescado, a quien se acusara del delito de cargar armas prohibidas, $y$ a quien se negara su profesion de pescador? Y viceversa; si el acusado es uno de esos cuyo oficio es pescar ¿cómo se acomodaria con él? Al tenor de esto, hai muchas otras voces de uso vulgar anfibolójico que pueden hacer zozobrar; y para evitar esto, no se conoce mas remedio que la propiedad, la exactitud, y un poco de estudio sobre lo que llevamos diariamente entre manos, y hemos menester en los mas importantes actos de la vida (Gormaz, 1860, p. v).

Gormaz subraya que mientras que en el español chileno pescador tiene dos significados, la variedad estándar codificada en el diccionario de la Real Academia Española distingue entre pescador 'persona que captura peces' y pescadero 'persona que vende pescado'. En este sentido, la variedad estándar tiene para Gormaz la ventaja de ser más “exacta”, siendo así más útil para la comunicación y la interacción social. 
Algunos años más tarde, en 1866, el político conservador, historiador y periodista Ramón Sotomayor Valdés (1830-1903) leyó en la Facultad de Filosofía de la Universidad de Chile un discurso sobre "La Formación del Diccionario hispano-americano" (véase Rojas, 2014 para un análisis detallado de la ideología lingüística de este autor).

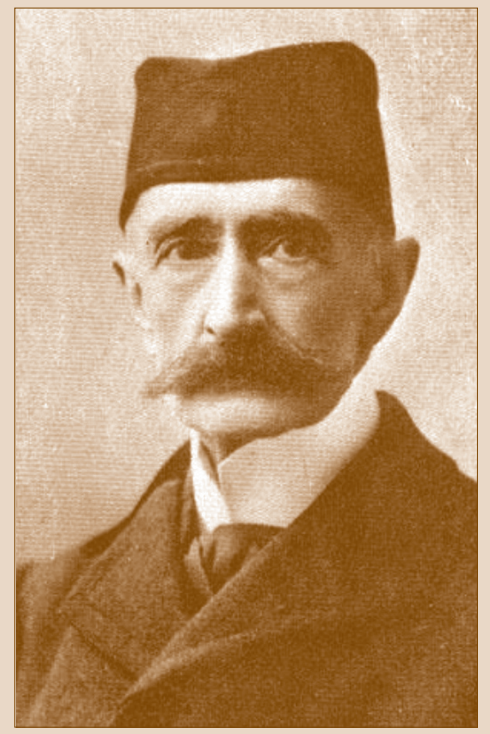

Ramón Sotomayor Valdés. Imagen tomada de www.memoriachilena.cl

En su discurso, Sotomayor se refiere a las funciones que un diccionario hispanoamericano debería cumplir. Entre estas funciones está la de "fijar el sentido jenuino de muchos vocablos", los cuales "vagan a la aventura i a merced del capricho de las circunstancias" (Sotomayor, 1866, p. 677). La función estandarizadora (revelada aquí en el uso del verbo fijar, acción entendida como freno de la variación semántica) atribuida al diccionario tiene relación con una función más general: la construcción de un principio de autoridad en asuntos lingüísticos. Esta última función, la "autoritaria", tiene una relación evidente con los ideales políticos de los conservadores chilenos, grupo político al que pertenecía Sotomayor (véase Brahm, 1992).

En 1875, el político liberal-católico y abogado Zorobabel Rodríguez (1839-1901) publicó su Diccionario de chilenismos, la primera obra lexicográfica de gran envergadura dedicada a recoger (y corregir) las variantes no estándares del español de Chile. Rodríguez no es ambiguo en absoluto 
cuando declara su opinión sobre el español de Chile. La frase con que inicia el prólogo de su diccionario es la siguiente "La incorrección con que en Chile se habla y escribe la lengua española es un mal tan generalmente reconocido como justamente deplorado" (Rodríguez, 1875, p. vii).
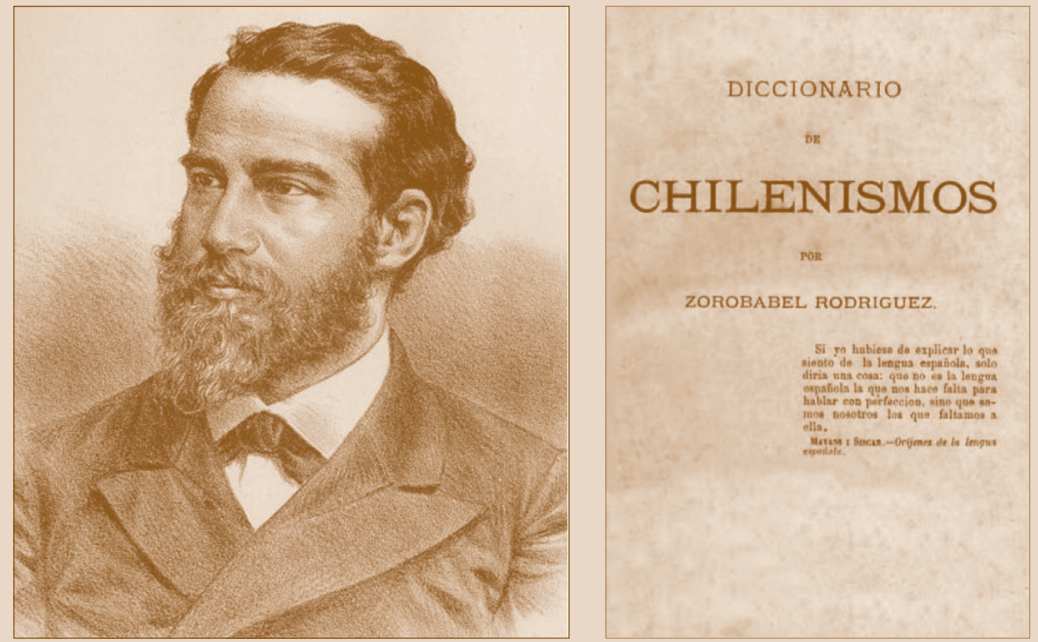

Zorobabel Rodríguez y su Diccionario de chilenismos. Imágenes tomadas de www. memoriachilena.cl

Para Rodríguez, el Diccionario de la Real Academia Española es un principio de autoridad. En consecuencia, el lexicógrafo chileno cita muy a menudo esta obra al justificar su opinión de que los hispanohablantes chilenos utilizan incorrectamente una palabra dada:

\section{DISTRAIDO.}

No es el que fija poco la atención en las cosas que hace o dice, el desatento; sino "el entregado a la vida licenciosa i desordenada." (Diccionario de la Academia.) (Rodríguez, 1875, p. 194).

$\mathrm{Al}$ igual que en Sotomayor, observamos aquí la idea de que el diccionario de la Real Academia Española tiene la autoridad para determinar cuál es el sentido propio de la palabra. Esto, a su vez, implica la creencia de que las palabras debieran tener un significado propio y único.

Si buscamos con cuidado en el Diccionario de Rodríguez, encontramos ejemplos que revelan la creencia de que, siendo la polisemia una caracte- 
rística casi inevitable del lenguaje (como Andrés Bello había reconocido), el gramático o lexicógrafo normativo solo puede aspirar a evitar la adición de más significados a los ya existentes. En términos generales, Rodríguez muestra una actitud negativa hacia los casos de polisemia donde el "nuevo" significado se usa solo en Chile (o en algún otro país de habla española de América), mientras que el significado "antiguo", el ya existente, se utiliza en España o se incluye en diccionarios generales (tales como el Diccionario de la Real Academia Española).

En el siguiente caso, la palabra ya es polisémica incluso antes de considerar el uso chileno. Sin embargo, estos significados preexistentes ya tienen la "aprobación" del diccionario de la Academia (y de otros diccionarios). En consecuencia, Rodríguez solo se siente capaz de criticar específicamente el significado dialectal chileno:

PADRON.

No tiene entre sus acepciones castizas i autorizadas por los diccionarios de la lengua la de caballo padre, que le damos en Chile (Rodríguez, 1875, p. 342).

El sacerdote salesiano Camilo Ortúzar (1848-1895) es otro ejemplo de la actitud negativa que hemos venido ilustrando. Su Diccionario manual de locuciones viciosas (1893) es tal vez el mejor ejemplo de la naturaleza normativa y homogeneizante de los discursos metalingüísticos chilenos del siglo XIX.

En el prólogo de esta obra, Ortúzar declara lo siguiente:

Para expresar con verdad y gracia el pensamiento, para que éste refleje con toda exactitud [...] el lucimiento y esplendor que alcanzó el lenguaje en su época de gloria, es necesario conocer el significado propio de los términos y distinguir las buenas de las malas locuciones (Ortúzar, 1893, pp. X-xi).

La referencia al "significado propio" de las palabras es coherente con sus críticas a "las odiosas anfibologías que resultan de dar nuevas acepciones a las palabras y frases usuales" (Ortúzar, 1893, p. xvi). El sacerdote aplica este criterio a lo largo de las entradas de su diccionario: por ejemplo, declara que adjuntar es "innecesario [...] y además anfibológico" (Ortúzar, 1893, p. 13).

En conclusión: en lo que respecta a la polisemia, como en muchos otros aspectos de las ideologías lingüísticas del siglo XIX chileno, hay una relativa 
uniformidad de opinión entre los miembros de la élite hispanohablante. La ideología de la lengua estándar es, de hecho, el marco de pensamiento hegemónico en la época. Puede afirmarse, sin lugar a duda, que los miembros de la élite cultural chilena conformaban una comunidad discursiva (Watts 2008), ya que compartían intereses, metas y creencias acerca de la lengua española.

Pero dicha convergencia no es absolutamente homogénea, como es razonable esperar si consideramos que las ideologías lingüísticas casi nunca se dan de modo absolutamente homogéneo dentro de un grupo (Woolard, 1998, p. 6). Una opinión divergente respecto de la polisemia, en el caso del Chile del XIX, pertenece a Fidelis del Solar, quien comparte, no obstante, en muchos otros puntos, la ideología de la lengua estándar.

En un comentario de 1876 al Diccionario de chilenismos de Rodríguez, Del Solar da cuenta de la desaprobación de Rodríguez de la polisemia y expresa su desacuerdo con esta actitud. Afirma que "podemos crear acepciones nuevas a palabras semejantes en el sentido que necesitamos emplearlas" (Del Solar, 1876, p. ix). La razón es que "si cada palabra no tuviera mas que una sola acepcion, necesitariamos cuadruplicar por lo ménos el caudal de voces de la lengua española" (Del Solar, 1876, p. xi).

Del Solar primero se refiere a la "necesidad" de un nuevo significado. La idea de la necesidad (es decir, la ausencia de una palabra para nombrar un concepto, que justifica el neologismo) es un argumento habitual a favor de las innovaciones lingüísticas en el discurso metalingüístico chileno del siglo XIX (Avilés y Rojas, 2014, p. 154). En segundo lugar, su justificación se refiere a la economía de la forma: piensa que la adición de nuevos significados es mejor que la adición de nuevas palabras. Sin embargo, no explica por qué esto sería una mala cosa (siempre y cuando se necesiten esas palabras para nombrar los nuevos conceptos, ¿por qué deberían ser censurados?).

\section{CONCLUSIÓN}

Las actitudes negativas hacia la polisemia, exhibidas por los gramáticos y lexicógrafos chilenos del siglo XIX, fueron producto de una versión circunstanciada de la ideología de la lengua estándar. Dado que la estandarización se centra en la reducción de la variación, podemos entender que los estudiosos interesados en implementar la estandarización hayan mostrado una actitud negativa hacia la polisemia, porque esta característica lingüística implica la existencia de más de un significado para una forma léxica, 
esto es, variación semasiológica. Esta variación, según la opinión de los autores estudiados, sería perjudicial para la comunicación eficiente (y para la unidad política). Se puede ver además cómo, en el marco de la ideología hispánica del estándar, que considera los códigos de la RAE como fuente de legitimidad, no todos los casos de polisemia son igualmente negativos: no son censurados los casos en que los sentidos de una palabra polisémica están "autorizados" por el Diccionario de la RAE. Es decir, se trata de evitar la polisemia "en la medida de lo posible".

Las ideas sobre la polisemia analizadas en el presente trabajo tienen raíces en antiguas tradiciones retóricas y de reflexión gramatical, pero, en lugar de abordar dicha línea indagatoria (en una línea más afín a la historiografía lingüística tradicional, que habría dado lugar a un trabajo distinto), hemos preferido subrayar el hecho de que el contexto sociopolítico específico es muy importante para entender por qué una idea dada sobre el lenguaje llega a ser común entre un grupo de intelectuales durante un período determinado. La ideología de la lengua estándar y la reducción de la variación lingüística calzan muy bien con las ideas culturalmente conservadoras de los autores chilenos que hemos estudiado. Las ideas globales de "orden" y "control", que funcionan a nivel general en el ámbito político, son coherentes, en un nivel más específico, con la idea de restringir la polisemia y convertir así el lenguaje en una herramienta comunicativa de máxima eficacia, útil para los propósitos unificadores del Estado-nación. La adición de nuevos significados a las palabras era una de esas transgresiones del orden (conducentes al caos, en potencia) que la élite chilena de habla española no podía tolerar.

\section{REFERENCIAS}

Arnoux, E. (2008). Los discursos sobre la nación y el lenguaje en la formación del Estado (Chile, 1842-1862). Estudio glotopolítico. Buenos Aires: Santiago Arcos.

Auroux, S. (2009). A revolução tecnológica da gramatização. Translated by Eni Puccinelli Orlandi. Second edition. Campinas: Unicamp.

Avilés, T. y Rojas, D. (2014). "Argumentación y estandarización lingüística: creencias normativas en el Diccionario de chilenismos (1875) de Zorobabel Rodríguez". Revista Signos. Estudios de Lingüística, 85, 142-163.

Bello, A. (1847). Gramática de la lengua castellana destinada al uso de los americanos. Santiago: Imprenta del Progreso.

Bello, A. (1883). "Correcciones lexicográficas”. En: Amunátegui Reyes, M. L. 
(Ed.). Obras completas de don Andrés Bello. Tomo VIII: Opúsculos literarios i críticos III, lxix-lxxvii. Santiago: Imprenta de Pedro Ramírez.

Blommaert, J. (Ed.). (1999). Language Ideological Debates. Berlin \& New York: Mouton de Gruyter.

Brahm, E. (1992). "La crisis del conservantismo chileno en la segunda mitad del siglo XIX. Política, gobierno y régimen de gobierno en el itinerario intelectual de don Ramón Sotomayor Valdés". Revista Chilena de Derecho, 19(1), 7-33.

Collier, S. y Sater, W. F. (2004). A History of Chile, 1808-2002. 2a ed. Cambridge: Cambridge University Press.

Cruse, D. A. (2004). "Contextual variability of meaning”. En: Meaning in Language. An Introduction to Semantics and Pragmatics, 2a ed., 101-122. Oxford: Oxford University Press.

Del Solar, F. (1876). Reparos al "Diccionario de chilenismos" del señor don Zorobabel Rodríguez. Santiago: Imprenta de Federico Schrebler.

Garrett, P. (2010). Attitudes to Language. Cambridge: Cambridge University Press.

Geeraerts, D. ([2003] 2006). "Cultural models of linguistic standardization". En: Words and other wonders. Papers on lexical and semantic topics (pp. 272306). Berlin \& New York: Mouton de Gruyter.

Gormaz, V. (1860). Correcciones lexigráficas sobre la lengua castellana en Chile. Valparaíso: Imprenta del Comercio.

Jaksić, I. (2001). Andrés Bello: Scholarship and Nation-Building in nineteenthcentury Latin America. Cambridge: Cambridge University Press.

Kroskrity, P. V. (2010). “Language ideologies - Evolving perspectives”. En: Jaspers, J., Östman, J-O., y Verschueren, J. (Eds.). Society and Language Use (pp. 192-211). Amsterdam/Philadelphia: John Benjamins.

Maio, G. R., Olson, J. M., Bernard, M. M., y Luke, M. A. (2006). "Ideologies, Values, Attitudes, and Behavior”. En: Delamater, J. (Ed.). Handbook of Social Psychology (pp. 283-308). New York: Springer.

Milroy, J. (2001). "Language ideologies and the consequences of standardization". Journal of Sociolinguistics, 5(4), 530-555.

Milroy, J. y Milroy, L. (1999). Authority in Language: Investigating Standard English. London: Routledge.

Nerlich, B. (2003). "Polysemy: past and present". En: Nerlich, B., Todd, Z., Herman, V., y Clarke, D. (Eds.). Polysemy: Flexible Patterns of Meaning in Mind and Language (pp. 49-76). Berlin \& New York: Mouton de Gruyter.

Ortúzar, C. (1893). Diccionario manual de locuciones viciosas y de correcciones de lenguaje. San Benigno Canavese: Imprenta Salesiana.

Piantadosi, S. T., Tily, H., y Gibson, E. (2012). "The communicative function of ambiguity in language". Cognition, 122, 280-291.

Rodríguez, Z. (1875). Diccionario de chilenismos. Santiago: Imprenta de El Independiente. 
Rojas, D. (2010). "Estandarización lingüística y pragmática del diccionario: forma y función de los 'diccionarios de provincialismos' chilenos". Boletín de Filología, XLV(1), 209-233.

Rojas, D. (2011). "La polisemia léxica regular y las facetas en la lexicografía del español". Boletín de Filología, XLVI(1), 163-205.

Rojas, D. (2014). "Diccionario y estandarización lingüística en Hispanoamérica: la visión de Ramón Sotomayor Valdés (1866)”. Estudios Filológicos, 53, 109-121.

Sand, L. (1958). The role of Federico Hanssen and Rodolfo Lenz in the intelectual life of Chile. Tesis doctoral, Universidad de Carolina del Norte, EE.UU.

Sotomayor, R. (1866). “Formación del Diccionario hispano-americano". Anales de la Universidad de Chile, XXVIII(10), 665-681.

Subercaseaux, B. (2011). Historia de las ideas y la cultura en Chile: desde la Independencia hasta el Bicentenario. Tomo 1, volumen 1: Sociedad y cultura liberal en el siglo XIX. Santiago: Editorial Universitaria.

Swiggers, P. (2012). "Linguistic historiography: object, methodology, modelization". Todas as Letras, 14(1), 38-53.

Velleman, B. L. (2002). "Linguistic anti-academicism and Hispanic community: Sarmiento and Unamuno". En: Del Valle, J., y Gabriel-Stheeman, L. (Eds.). The Battle over Spanish between 1800 and 2000. Language ideologies and Hispanic intellectuals (pp. 14-41). London \& New York: Routledge.

Watts, R. J. (2008). "Grammar writers in eighteenth-century Britain: A community of practice or a discourse community?". En: Tieken-Boon van Ostade, I. (Ed.). Grammars, Grammarians and Grammar-Writing in EighteenthCentury England (pp. 37-56). Berlin \& New York: Mouton de Gruyter.

Wilton, A. y Wochele, H. (2011). "Linking past and present. A view of historical comments about language". AILA Review, 24, 55-67.

Woolard, K. A. (1998). "Introduction: Language Ideology as a Field of Inquiry". En: Schieffelin, B. B., Woolard, K. A., y Kroskrity, P. V. (Eds.). Language Ideologies. Practice and Theory (pp. 3-47). Oxford: Oxford University Press. 